\title{
The Spice Kitchen: Apprenticeship Training in Culinary Skills
}

\author{
Marie Fanelli Kuczmarski, Elisabeth M. Jones \\ Department of Behavioral Health and Nutrition, University of Delaware, Newark, USA \\ Email:mfk@udel.edu, ejones@udel.edu
}

Received October $11^{\text {th }}, 2012$; revised November $15^{\text {th }}, 2012$; accepted November $28^{\text {th }}, 2012$

\begin{abstract}
Current Dietary Guidelines for Americans emphasize the need to reduce dietary sodium. Spices impart flavor to food, serving as substitutes for salt. In addition, the antioxidant activity of spices can provide health benefits. Dietetic students receive training in basic food preparation and foodservice management however, their knowledge and use of spices can be limited. This article describes the enhancement of their culinary experiences through participation in a class designed to explore the flavors and health properties of 10 spices. The class provided an opportunity for apprenticeship training, exposing students to spices and cooking methods. Student objectives were: 1) to increase knowledge of spices and their potential health benefits; 2) to use flavorful swaps, substituting spices for salt in daily food preparation; 3) to identify and evaluate the intensity of aromas associated with selected spices; and 4) to gain ex- perience utilizing cooking methods that reduce fat in preparation. All of the objectives were achieved based on student responses to pre-, mid-, and post-course evaluations and the completion of aroma charts for each lab. Course challenges such as food costs and space availability were identified but easily managed. To our knowledge this is the first class devoted to spices in a didactic dietetics accredited program in the United States. Training dietetic and other health professional students, about the use of spices to enhance flavor when reducing the sodium, fat and sugar content of foods may be beneficial to their clients who are trying to manage not only their weight but also other medical conditions such as hypertension and diabetes mellitus.
\end{abstract}

Keywords: Spices; Culinary Class; Dietetic Education; Food Preparation; Antioxidants

\section{Introduction}

People's knowledge and experience cooking with a wide variety of foods as well as with spices and herbs may be limited. A decline in cooking skills in young adult populations has been observed, which may be attributed to a decrease in confidence in preparing quick and healthful meals (Caraher et al., 1999). Larson and colleagues (2006) reported that a lack of confidence in cooking skills, as well as a dislike of cooking can act as barriers for food preparation (Crawford et al., 2007) resulting in a decrease in healthful food consumption, particularly fruits and vegetables.

From 1977 to 1995 , home cooking decreased while eating out at sit-down or fast food restaurants increased by about 200\% (Lin et al., 1999). Though many establishments have included "healthy" options on their menu, dishes consumed outside of the home typically contain more sodium and energy compared to home-cooked meals (Bruemmer et al., 2012). Furthermore, eating out is also associated with weight gain (Obbagy \& Essery, 2012). Thus, if people could be encouraged to prepare tasty foods and eat out less frequently, they would be less likely to gain weight and would consume less sodium. Additionally, the consumption of a diet high in sodium, fat, and refined grains, and low in fruits and vegetables has resulted in increased risk for developing several chronic illnesses such as obesity, cardiovascular disease, type 2 diabetes mellitus, and selected cancers (Cordain et al., 2005).

The mean daily sodium consumption of the US population is about $3463 \mathrm{mg}$ (USDA, 2012), a level that exceeds the $\leq 2300$ $\mathrm{mg}$ recommendation in the Dietary Guidelines for Americans 2010 (2010). This recommendation applies to all Americans with the exception of the special US populations groups (persons 51 years of age and older, and persons of any age who are African American, or have hypertension, diabetes or chronic kidney disease). The daily recommended level for these special groups is $1500 \mathrm{mg}$ sodium. Spices impart flavor, the combination of taste and aroma, to food so they can be used as a salt substitute. Spices can not only enhance the aroma of foods, stimulating taste buds, but also have health benefits.

Our knowledge about the health promoting properties of spices in humans has not been fully elucidated. Data from in vitro and animal studies suggest that most of the health effects on cardiovascular disease, cancer, diabetes, and mental health maybe mediated through the potent antioxidant action of spices (Carlsen et al., 2010; Gruenwald et al., 2010; Kaefer \& Milner, 2008; Tapsell, 2008; Viuda-Martos et al., 2011). Spices contain not only essential oils (Viuda-Martos et al., 2007), but also bioactive compounds which are responsible for their functional properties (Aggarwal et al., 2007; Amagase et al., 2001; Gardner et al., 2003; Kaefer \& Milner, 2008; Kochhar, 2008; Ozcan \& Chalchat, 2009; Qin et al., 2010; Viuda-Martos et al., 2011) (Table 1). The polyphenols provide antioxidant (Gruenwald et al., 2010; Jungbaurer \& Medjakovic, 2012; Kaefer \& Milner, 2008; Kochhar, 2008; Li et al., 2010; Singletary, 2010c), antibacterial (Kaefer \& Milner, 2008), antiviral (Kochhar, 2008; Benencia \& Courreges, 2000; Tragoolpua \& Jatisatienr, 2007; Viuda-Martos et al., 2011), antidiabetic (Gruenwald et al., 2010, Jungbaurer \& Medjakovic, 2012; Qin et al., 2010, Singletary, 2010c; Srinivasan, 2005; Viuda-Martos et al., 2011), anti-inflammatory (Frenech, 2006; Kaefer \& Milner, 2008; Kochhar, 2008; Jungbaurer \& Medjakovic, 2012; Singletary, 2010a, 2010b, 
Table 1.

Bioactive components and action of selected spices.

\begin{tabular}{|c|c|c|}
\hline Spice & Bioactive Components ${ }^{\mathrm{a}}$ & Potential Action \\
\hline Cinnamon & $\begin{array}{l}\text { Cinnamic aldehyde, } \\
\text { 2-hydroxycinnamaldehyde, } \\
\text { Eugenol }\end{array}$ & $\begin{array}{l}\text { Antioxidant } \\
\text { Anti-diabetic (potentiates insulin effect) } \\
\text { Anti-inflammatory }\end{array}$ \\
\hline Cloves & $\begin{array}{l}\text { Eugenol, } \\
\text { Isoeugenol, } \\
\text { Gallic acid }\end{array}$ & $\begin{array}{l}\text { Antioxidant } \\
\left.\text { Antiviral activity (HSV-1, HSV-2 }{ }^{b}\right)\end{array}$ \\
\hline Cumin & $\begin{array}{l}\text { Carvone, Carvacrol, } \beta \text {-carotene, Cuminaldehyde, Limonene, } \alpha \text { and } \beta \text {-pinene, } \beta \text {-sitosterol, } \delta \text {-terpinene, } \\
\text { Thymol }\end{array}$ & $\begin{array}{l}\text { Antioxidant } \\
\text { Anti-diabetic } \\
\text { Hypolipidemia effect }\end{array}$ \\
\hline Garlic & Allicin, Allyl isothiocyanate, Diallyl disulfide & $\begin{array}{l}\text { Anti-diabetic } \\
\text { Hypolipidemia effect }\end{array}$ \\
\hline Ginger & $\begin{array}{l}\text { Curcumin, Gingerols, Ingerol, } \\
\text { Paradol, Shogaol, Zingiberone, Zingiberene }\end{array}$ & $\begin{array}{l}\text { Antioxidant } \\
\text { Antibacterial } \\
\text { Anticarcinogenic } \\
\text { Anti-inflammatory }\end{array}$ \\
\hline Oregano & $\begin{array}{l}\text { Apigenin, Caffeic acid, Carvacrol, } \rho \text {-coumarin, Ferulic acid, Luteolin, Myricetin, Quercetin, } \\
\text { Rosmarinic acid, Terpenes, Thymol }\end{array}$ & $\begin{array}{l}\text { Antioxidant } \\
\text { Antibacterial } \\
\text { Anti-inflammatory } \\
\text { Antimicrobial } \\
\text { Antiviral (HIV-1 }{ }^{\circ} \text { ) }\end{array}$ \\
\hline Rosemary & $\begin{array}{l}\text { Apigene, Caffeic acid, Carnasol, Carnosic acid, } \beta \text {-carotene, Cineole, Geraniol, Limonene, Luteolin, } \\
\alpha \text {-pinene, Narginin, Ursolic acid, Rosmarinic acid, Rosmanol, Vanillic acid }\end{array}$ & $\begin{array}{l}\text { Antioxidant } \\
\text { Anticarcinogenic } \\
\text { Anti-inflammatory } \\
\text { Antiviral (HIV) }\end{array}$ \\
\hline Thyme & $\begin{array}{l}\text { Thymol, Carvacrol, Cineole, } \alpha \text {-pinene, } \beta \text {-carotene, Apigene, Limonene, Eugenol, Ursolic acid, Luteolin, } \\
\text { Gallic acid, Caffeic acid, Rosmarinic acid, Carnosic acid, Hispidulin, Cismaritin, Chlorogenic acid }\end{array}$ & $\begin{array}{l}\text { Antioxidant } \\
\text { Anti-inflammatory } \\
\text { Antiviral (HIV-1) }\end{array}$ \\
\hline Turmeric & Caffeic acid, Curcumin, Curcuminoids, p-coumaric acid, Ferulic acid, Syringic acid & $\begin{array}{l}\text { Antioxidant } \\
\text { Anticarcinogenic } \\
\text { Anti-diabetic } \\
\text { Anti-inflammatory }\end{array}$ \\
\hline
\end{tabular}

Note: ${ }^{\mathrm{a} L i s t e d}$ alphabetically; ${ }^{\mathrm{b}} \mathrm{HSV}$ — herpes simplex virus; ${ }^{\mathrm{c}} \mathrm{HIV}$ - human immunodeficiency virus.

2010c), anticarcinogenic (Aggarwal et al., 2007; Frenech, 2006; Kochhar, 2008; Singletary, 2010c; Tapsell, 2008; Tayyem et al., 2012), and hypolipidemic action (Amagase et al., 2001; Gardner et al., 2003; Jungbaurer \& Medjakovic, 2012; Kochhar, 2008; Patch \& Sullivan, 2006; Tapsell, 2008; Sultan et al., 2011).

Registered dietitians (RDs) are recognized as experts in the role of food and nutrition in health. However, RDs may not necessarily be culinary connoisseurs. The addition of spices is one way to retain taste and flavor when reducing the sodium, fat and sugar of foods. Knowledge of the aromas of a wide variety of spices allows an individual the ability to combine different spices to create foods with more complex and intense flavor profiles. Based on a review of 229 accredited didactic dietetic programs across the US (Academy of Nutrition and Dietetics, 2012), it appears that students trained to become RDs are not exposed to spices in any depth even though they are required to complete basic food and quantity food courses. This review revealed 1 class period devoted to spices in a program entitled, "Healthy Eating in American Cuisine" at California State Polytechnic University (2012), a spice drive at Louisiana State University (2012) to show individuals that tasty food does not depend on salt, and "Spice it Up; Herbs and Spices Cooking Class", a one time fee event, sponsored by Bernalillo County Cooperative Extension Service (New Mexico State University, 2012). Since many RDs counsel people and create messages for consumers to reduce their sodium, it is our opinion that all nu- trition and dietetics programs should provide future RDs with exposure and culinary experiences with spices.

The objective of this manuscript is to describe the educational and practical benefits of a culinary class designed to explore the aromas, flavors, and health properties of 10 spices which could be healthful alternatives to salt as a seasoning.

\section{Methods}

\section{Student Characteristics}

A total of 18 college students -2 males and 16 females comprised the sample. Of these 18,11 were majoring in dietetics and the remaining students were majoring in health behavior, exercise science, or medical laboratory sciences and diagnostics. The study procedures were approved by the Institutional Review Board of the University of Delaware.

\section{Course Description}

The course was titled "The Spice Kitchen: Taste the Flavor". The objectives of the course were: 1) to enhance the student's knowledge of spices and the health benefits associated with spices; 2) to experience the aromas and flavors of a variety of spices and encourage the use of spices in lieu of salt; 3) to introduce students to the art and science of food tasting and to gain some proficiency in aroma identification; and 4) to gain 
experience utilizing cooking methods that minimize the use of fat in preparation. This 1-credit elective class met for two hours each week during the semester. There were a total of 14 classes, of which 4 were presentations and 10 were spice labs. The first class reviewed food safety and provided an introduction to resources and policies related to the food lab. The presentation on food safety was given by a University of Delaware Cooperative Extension staff member. The next class was a presentation given by a representative from a spice company who described the production and processing of spices, discussed the aromas of spices, and lead a hands-on aroma sensory demonstration. An aroma chart of the spices covered in the class was distributed (Table 2) (Civille \& Lyon, 1996; McCormick Science Institute, 2012). The other two lectures focused on the health properties of spices. The 10 spice labs were devoted to preparing recipes, tasting and evaluating each recipe, and then discussing aromas and recipe modifications.

Given the class time allotted, each spice lab was created to consist of approximately 40 minutes for the recipe preparation with discussion about spices and certain recipe ingredients and exposure to the aromas associated with the featured spice, 30 minutes for the tasting and student completion of sensory evaluation sheets, 5 minutes to summarize the sensory evaluation sheets, 25 minutes for discussion of aroma evaluations and acceptability ratings, and 20 minutes for clean-up. Set-up for each class was done prior to the class and required about an hour.

The course was first taught in fall 2011 in the departmental food laboratory. The room was designed to have sufficient space for an enrollment of 18 students. This classroom had 6 cooking stations and was equipped with a mirrored demonstration table. In order to minimize the expense of the course, only the instructor with the aid of a teaching assistant, and two enrolled students with the assistance of a second teaching assistant prepared the recipes each week. Different students assisted with the food preparation each week. This design allowed all students hands-on experience, as well as yielded enough food for everyone to taste.

\section{Spice and Recipe Selection}

Since the course had an underlying theme of health, spices with antioxidant properties or other documented health benefits were chosen. The spices selected were the following: cinnamon, cloves, cumin, curry, garlic, ginger, oregano, rosemary, thyme, and turmeric.

The selection of recipes was based on several criteria. These criteria included: healthfulness of the recipe (such as use of whole grains, foods low in fat), ease of preparation and expense for a college student, preparation and cooking under 60 minutes, recipes that represent different components of a meal (appetizer, entrée, side dishes, desserts), and recipes that were palatable with other recipes in the lab curriculum. The intent was to expose the students to not only healthful recipes, but also methods of preparation that minimized the use of fats and oils. Thus, a Rival Crock-Pot ${ }^{\circledR}$, George Forman ${ }^{\circledR}$ removable plate grill and Tefal $^{\circledR}$ Actifry were used. (The ActiFry uses pulsed hot air

Table 2.

Descriptors of aroma of selected spices.

\begin{tabular}{|c|c|c|c|c|c|c|c|c|c|c|}
\hline Descriptors & Cinnamon & Cloves & Cumin & Curry $^{\mathrm{a}}$ & Garlic & Ginger & Oregano & Rosemary & Thyme & Turmeric \\
\hline Astringent mouthfeel & $\sqrt{ }$ & & & & & & $\sqrt{ }$ & & & \\
\hline Bite/Heat & $\sqrt{ }$ & & & $\sqrt{ }$ & & $\sqrt{ }$ & & & & \\
\hline Bitter & & & & & $\sqrt{ }$ & & $\sqrt{ }$ & & & $\sqrt{ }$ \\
\hline Carvone (d-caraway) & & & $\sqrt{ }$ & & & & & & & \\
\hline Cinnamic Aldehyde & $\sqrt{ }$ & & & & & & & & & \\
\hline Dirty & & & & & & & & $\sqrt{ }$ & & \\
\hline Earthy & $\sqrt{ }$ & & $\sqrt{ }$ & & & $\sqrt{ }$ & $\sqrt{ }$ & & & $\sqrt{ }$ \\
\hline Eugenol & & $\sqrt{ }$ & & & & & & & & \\
\hline Fruity & & $\sqrt{ }$ & & & & & & & & \\
\hline Green, General & & & some & & $\sqrt{ }$ & & $\sqrt{ }$ & & $\sqrt{ }$ & \\
\hline Hay & & & & & & & $\sqrt{ }$ & $\sqrt{ }$ & $\sqrt{ }$ & \\
\hline Heat & & & & & $\sqrt{ }$ & $\sqrt{ }$ & & & & \\
\hline Hydrogen Sulfide & & & & & $\sqrt{ }$ & & & & & \\
\hline Medicinal (camphorous) & & & & & & & & $\sqrt{ }$ & $\sqrt{ }$ & \\
\hline Metallic & & & & & $\sqrt{ }$ & & & & & \\
\hline Minty & & $\sqrt{ }$ & & & & & $\sqrt{ }$ & & & \\
\hline Musky & & & & $\sqrt{ }$ & & & & & & $\sqrt{ }$ \\
\hline Musty, General & $\sqrt{ }$ & & $\sqrt{ }$ & & $\sqrt{ }$ & $\sqrt{ }$ & $\sqrt{ }$ & & & \\
\hline Numbing & & $\sqrt{ }$ & & & & & & & & \\
\hline Pine & & & $\sqrt{ }$ & & & & & $\sqrt{ }$ & & \\
\hline Sweet & $\sqrt{ }$ & & & $\sqrt{ }$ & $\sqrt{ }$ & & & & & \\
\hline Woody & $\sqrt{ }$ & $\sqrt{ }$ & & & & & & $\sqrt{ }$ & & \\
\hline Sweet aromatics & $\sqrt{ }$ & $\sqrt{ }$ & & & & $\sqrt{ }$ & & & & \\
\hline
\end{tabular}

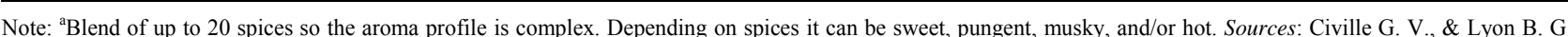
(1996). Aroma and Flavor Lexicon for Sensory Evaluation: Terms, Definitions, References, and Examples. West Conshohocken, PA, American Society for Testing and Materials (ASTM) International. McCormick Science Institute. http://www.mccormickscienceinstitute.com. Last Update: NA, Last checked 11October 2012. 
with a mixing paddle to cook foods. It requires the use of minimal fat; for example, 2 pounds of French fries require only 1 tablespoon of oil.)

The recipes selected were obtained from websites, mainly McCormick $^{\circledR}$ (2012) Cabot $^{\circledR}$ (2012) and from the cookbooks associated with the Crock-Pot ${ }^{\mathbb{B}}$ and ActiFry. Salt was eliminated from all recipes. The recipes were prepared and evaluated during the semester prior to the class offering. On occasion modifications to cooking times were made to accommodate the use of the Actifry in place of traditional methods. Realizing that some of the students may be vegetarians, certain recipes were modified using alternative protein sources or vegetables in place of meat. For example, portabella mushrooms were substituted for chicken in a grilling recipe.

\section{Evaluations}

\section{Sensory Evaluations}

Students performed both analytical evaluations (ranking the intensity of aromas) and affective evaluations (rating the overall acceptability of each recipe using hedonic scales). Prior to completing the evaluations, the ladder of success from taste to acceptability was discussed. Students learned that the basic tastes perceived by the human brain include sweet, salty, bitter, sour, and umami. Tastes are hardwired. The full flavor of the food emerges when the basic tastes are combined with the sense of smell and touch. Smells are learned through experience. The palatability of a food results from the combination of flavor with the senses of vision and hearing. To fully appreciate a food, an individual's personal and cultural preferences must align with its palatability. Thus, the acceptability of a recipe is dependent upon the synergistic effects among taste, flavor, and palatability (Woods, 1998).

\section{Course Evaluations}

A pre-, mid-, and post-evaluation were done to measure the effectiveness of the course content in achieving the objectives. The pre-evaluation gathered information on the use of the ten selected spices and salt, frequency of food preparation, and food allergies and intolerances. The mid-course and post-evaluations gathered data on the use of spices and salt, preparation of recipes demonstrated in class, interest in learning more about spices as well as experimenting with spices, and ranking the spices by preference based on flavor and aroma attributes. The mid-course evaluation also asked students to write suggestions regarding changes they wanted to see implemented in the course. Quantitative research methods including in class and online evaluations were used to assess the success of the course.

\section{Results}

As shown in Table 3, with the exception of garlic, oregano and cinnamon, the majority of students did not typically use the remaining seven spices in their cooking. The acceptability of the recipes ranged from 1.73 (bread pudding) to 4.12 (spiced saffron jasmine rice), where 1 meant extremely liked and 7 meant extremely disliked (Table 3). These findings indicated that all the recipes with the exception of the spiced saffron jasmine rice were palatable and acceptable. The rating of the spiced saffron jasmine rice indicated that it was neither liked nor disliked. Of the 28 recipes tasted, there were only 5 recipes that more than half the students noted that they would add salt. These recipes included spiced saffron jasmine rice, curried pilaf, braised lentils, black bean salad, and rosemary bread dip (Table 3). Based on the students' ranking of the spices at the end of the semester, the preference from most to least favorite was garlic, cinnamon, oregano, rosemary, curry, cumin, ginger, thyme, turmeric, cloves.

\section{Self-Reflection}

After the students tasted and evaluated each recipe, they were asked if they would make the recipe for his/herself and if they would prepare the recipe for someone else. The responses to both questions were identical for each recipe. Fourteen students responded that they would prepare 27 of the 28 recipes for his/her self as well as others. Only five students reported they would prepare the spiced saffron jasmine rice for either his/ herself or someone else.

Seventeen of the 18 students reported on the post-evaluation that the class both sparked their interest in learning more about spices and in experimenting with spices. In addition, 9 of the 18 reported that the class increased their interest in culinary shows on TV and that they were watching more of these shows. Fifteen of the 18 stated that they were incorporating some of the spices into their current cooking.

A comparison of the pre- and post-evaluation responses to the question, "Do you add salt to the foods you prepare?" revealed an increase in the number of people stating "rarely" offset by a decrease in the number reporting "occasionally". With respect to the question, "Do you add salt at the table?" the number of "never" responses increased while the number of people reporting "rarely" decreased. These responses show a positive trend in reducing sodium intake, the direction recommended by the Dietary Guidelines for Americans, 2010 (2010).

\section{Course Evaluations}

In general the students revealed in the mid-course evaluation that they wanted to do more hands-on preparation. To accommodate this request the instructor became a narrator at the demonstration table while two additional students demonstrated the preparation of the recipes. Anonymous student responses from the university administered online course evaluations indicated that the course was a fun learning experience. One student wrote "it was interesting to see how the different spices worked together and how my salt intake could be reduced". Some comments indicated that the worksheets with questions for each spice contributed to their learning while others noted that the recipe sampling was very helpful for learning about the aromas. In addition, some students wrote that being able to participate in the demonstrations was the most helpful contribution to learning.

\section{Discussion}

To our knowledge this is the first class devoted to spices in a didactic dietetics accredited program in the United States. Even though the number of students enrolled in this university course was small, based on the course evaluations it was clearly evident that the objectives were achieved. The class not only exposed students to new spices and cooking methods but also provided opportunities for apprenticeship training of both undergraduate and graduate students, enhancing not only their skills 


\section{F. KUCZMARSKI, E. M. JONES}

Table 3.

Acceptability rating of recipes based on a 7-point Likert scale ${ }^{a}$ and use of spice and salt $(n=18)$

\begin{tabular}{|c|c|c|c|}
\hline Spice and Recipes & $\begin{array}{l}\text { Spice not typically used } \\
\text { (\#students) }\end{array}$ & $\begin{array}{l}\text { Acceptability rating } \\
(\mathrm{X} \pm \mathrm{SEM})\end{array}$ & $\begin{array}{l}\text { Would add salt } \\
\text { to recipe } \\
\text { (\#students) }\end{array}$ \\
\hline Cinnamon & 7 of 18 & & \\
\hline Warm and nutty quinoa & & $2.00 \pm .35$ & 0 of 18 \\
\hline Cinnamon chile crusted chicken & & $2.47 \pm .26$ & 2 of 18 \\
\hline Bread pudding & & $1.73 \pm .28$ & 0 of 18 \\
\hline $\begin{array}{l}\text { Black bean and veggie salad } \\
\text { with lime cinnamon vinaigrette }\end{array}$ & & $2.60 \pm .43$ & 1 of 18 \\
\hline Cloves & 17 of 18 & & \\
\hline Autumn apple brew & & $2.12 \pm .21$ & 0 of 18 \\
\hline Spiced saffron jasmine rice & & $4.12 \pm .30$ & 10 of 18 \\
\hline Braised lentils & & $2.82 \pm .25$ & 9 of 18 \\
\hline Cumin & 12 of 18 & & \\
\hline Spicy black bean salad with chicken & & $2.53 \pm .23$ & 1 of 18 \\
\hline Cumin fried rice & & $3.47 \pm .32$ & 7 of 18 \\
\hline Black bean salad & & $1.76 \pm .22$ & 15 of 18 \\
\hline Curry & 17 of 18 & & \\
\hline Curried pilaf & & $3.00 \pm .24$ & 11 of 18 \\
\hline Curried chicken salad & & $2.82 \pm .35$ & 1 of 18 \\
\hline Spicy Thai chicken curry & & $2.89 \pm .24$ & 5 of 18 \\
\hline Garlic & 0 of 18 & & \\
\hline Garlic and herb potatoes & & $2.07 \pm .25$ & 5 of 18 \\
\hline Greek tuna salad pockets & & $2.73 \pm .48$ & 2 of 18 \\
\hline $\begin{array}{l}\text { Edamame and corn salad } \\
\text { with oregano vinaigrette }\end{array}$ & & $2.20 \pm .28$ & 1 of 18 \\
\hline Ginger & 15 of 18 & & \\
\hline $\begin{array}{l}\text { Baby carrots with pecans and } \\
\text { ginger honey sauce }\end{array}$ & & $3.06 \pm .31$ & 1 of 18 \\
\hline Saucy chicken with pineapple & & $2.38 \pm .26$ & 0 of 18 \\
\hline Oregano & 1 of 18 & & \\
\hline Baked tomatoes oregano & & $2.07 \pm .27$ & 3 of 18 \\
\hline Mediterranean potato salad & & $2.28 \pm .18$ & 4 of 18 \\
\hline Pizza turkey burgers & & $1.94 \pm .21$ & 0 of 18 \\
\hline Rosemary & 10 of 18 & & \\
\hline Pepper rosemary bread dip & & $2.11 \pm .24$ & 10 of 18 \\
\hline Summer squash sauté & & $2.61 \pm .14$ & 7 of 18 \\
\hline $\begin{array}{l}\text { Rosemary pork and mushrooms } \\
\text { with shallots }\end{array}$ & & $3.06 \pm .28$ & 9 of 16 \\
\hline Thyme & 12 of 18 & & \\
\hline Mini thyme pepper burgers & & $2.78 \pm .40$ & 1 of 18 \\
\hline $\begin{array}{l}\text { Chicken and asparagus sauté } \\
\text { with thyme and lemon }\end{array}$ & & $2.33 \pm .29$ & 2 of 18 \\
\hline Turmeric & 18 of 18 & & \\
\hline $\begin{array}{l}\text { Turmeric roasted cauliflower } \\
\text { and tomatoes }\end{array}$ & & $3.73 \pm .40$ & 5 of 18 \\
\hline $\begin{array}{l}\text { Grilled Indian spiced flatbread pizza } \\
\text { with tomatoes and goat cheese }\end{array}$ & & $2.06 \pm .21$ & 2 of 18 \\
\hline
\end{tabular}

Note: ${ }^{\mathrm{a}}$ Likert scale with $1=$ Liked extremely; $2=$ Liked very much; $3=$ Liked moderately; $4=$ Neither liked or disliked; $5=$ Disliked moderately; $6=$ Disliked very much; and $7=$ Disliked extremely 
implementing culinary demonstrations but also their communication skills. For example, the semester prior to the class offering, the instructor mentored two undergraduate students who assisted with the development of spice fact sheets and testing of recipes. During the semester when the class was offered, the instructor supervised and mentored one undergraduate and one graduate student who served as teaching assistants.

In the 2012 Flavor Forecast released by McCormick for Chefs (2012), "flavorful swaps" is 1 of 6 global trends. Gaining knowledge about a variety of spices strengthened the students' cultural awareness about the flavors of food associated with diverse population groups. Smell preferences are learned and repeated exposures increase people's sensitivity to selected flavors. Thus, it will require time and repeated exposures to new aromas to change eating behaviors. Exposure to a variety of aromas and flavors may help students be better prepared to aid different population groups make healthier lifestyle changes.

A faculty member taught the flagship course and revised the curriculum where appropriate. Since the course is one that provides excellent training in nutrition education, the courses offered in the fall and spring 2012 semesters were taught by a nutrition graduate student who is an RD. This student attended all the classes in the 2011 fall semester. Her successful implementation of the class resulted in the department deciding that future classes can also be taught by trained nutrition graduate students with faculty available as mentors throughout the semester. The course quickly gained a positive reputation on campus. Consequently, maximum enrollment with a waiting list has been achieved, resulting in the department considering evening sections. The course in its entirety or as separate lessons on a given spice can be adapted to other settings in the community. Registered Dietitians, dietetic interns, dietary technicians, Cooperative Extension staff, nutritionists, and food scientists could serve as instructors.

Even though it has been estimated that there are at least 40 different seasonings currently available in US homes, compared to fewer than 10 in the 1950's (Reinagel, 2012), Americans may still be including salt in their cooking and at the table as a primary seasoning agent. People do recognize the components of a healthful diet but unfortunately, they think that low-fat foods and unsalted foods taste bland (Lucan et al., 2012). A narrow range of experience using different flavors, as well as limited knowledge of preparation techniques, reduce an individual's confidence to cook, especially with fruits and vegetables (Fazio et al., 2006) and may be adding to this reliance on salt. With over 300 different spices and herbs any food can possess great flavor given the knowledge of aromas.

One of the challenges of adding courses into undergraduate dietetic programs is the ability of the students to fit these elective courses into their schedule given the required didactic courses. Making the course 1 credit provided the flexibility to include this elective into current schedules. The course is currently opened to all students but the marketing of this class has been focused on students majoring in Behavioral Health and Nutrition. Given the interest in the class, if additional sections are offered, these classes could be marketed to other majors in the College of Health Sciences and College of Education and Human Development. Increasing the awareness of future health professionals and educators to the roles of RDs and the role of food in health would benefit the entire community.

This course was initiated voluntarily by a faculty member and was not part of an assigned teaching load. Administrative support was positive because the department chair perceived the class not only as recruitment tool, attracting students not majoring in dietetics to transfer into the major, but also as a way to increase student enrollment in the courses offered by the department. Even though faculty workloads may be at the maximum, the course can be taught by trained graduate students.

Another challenge in scheduling is the availability of the foods lab since at least an hour before the class is required for set-up. The ideal classroom would be a foods lab but this setting is not essential. Dining services at an educational institution may be willing to partner with faculty to offer culinary experiences. Since the cooking appliances and other utensils such as cutting boards, measuring spoons and bowls, are portable the critical components are a sink, tables, and chairs.

Lastly, there is a cost associated for the foods and spices. The initial set-up cost for the class which included the purchase of appliances (1 Crock-Pot ${ }^{\mathbb{B}}, 2$ grills and 2 Actifry ${ }^{\mathbb{B}}$ units), spices and ingredients to test the recipes, and miscellaneous items such as aprons and potholders was approximately $\$ 1400$. The average cost per semester to cover the expenses for recipe ingredients and disposable plates, cups, and cutlery for the sensory evaluations is approximately $\$ 750$. Our department decided not to charge a laboratory fee because the content of the course focused on one of the Commission on Accreditation for Dietetics Education foundation knowledge and competencies, namely techniques of food preparation and application to the development, modification and evaluation of recipes acceptable to diverse groups (Academy of Nutrition and Dietetics, 2012). However, the expenses could be offset by implementing a small laboratory fee per student.

\section{Conclusion}

To improve the health of our nation it is critical that Americans be motivated to not only reduce their sodium intake but also consume less of the Western diet characterized as a dietary pattern high in red and processed meats, refined grains, sodium, sweets, and fried foods. Using spices to add flavor and variety to energy and sodium-reduced meals may help motivate dietary change and reduce nutrition-related disease risk. Given the opportunity to experience a variety of spices and flavorful foods prepared without salt, the students' interest was sparked to learn more and incorporate more spices and less salt into their meals and meal preparation. Empowering students with the knowledge of the aromas of spices plus the potential health benefits of spices will make them better educators when advising people to trade their salt shaker for a spice shaker. Although there is no required intake level for spices and herbs, the Dietary Guidelines for Americans and dietary guidance of other countries like Australia recommend spice use (Tapsell, 2008). In conclusion, a culinary class focused on spices can enable college students and professionals to learn approaches to healthy flavorful cooking.

\section{REFERENCES}

Academy of Nutrition and Dietetics (2012). Didactic programs in dietetics. URL (last checked 3 October 2012).

http://www.eatright.org/BecomeanRDorDTR/content.aspx?id=8156\# .UE30D7J1R85

Aggarwal, B. B., Sundaram, C., Malani, N., \& Ichikawa, H. (2007). Curcumin: The Indian solid gold. Advances in Experimental Medicine and Biology, 595, 1-75. doi.org/10.1007/978-0-387-46401-5 1

Amagase, H., Petesch, B. L., Matsuura, H., Kasuga, S., \& Itakura, Y. (2001). Intake of garlic and its bioactive components. Journal of $\mathrm{Nu}$ - 
trition, 131, 955S-962S.

Benencia, F., \& Courreges, M. C. (2000). In vitro and in vivo activity of eugenol on human herpesvirus. Phytotherapy Research, 14, 495500 .

Bruemmer, B., Kriger, J., Saelens, B. E., \& Chan, N. (2012). Energy, saturated fat, and sodium were lower in entrees at chain restaurants at 18 months compared to 6 months following the implementation of mandatory menu labeling regulation in King County, Washington. Journal of the Academy of Nutrition and Dietetics, 112, 1169-1176. doi:10.1016/j.jand.2012.04.019

Cabot Recipes \& Pairings. URL (last checked 3 October 2012). http://www.cabotcheese.coop/pages/recipes/index.php

California State Polytechnic University. URL (last checked 3 October 2012).

http://www.csupomona.edu/ skapoor/syllabus.pdf

Caraher, M., Dixon, P., Lang, T., \& Carr-Hill, R. (1999). The state of cooking in England: the relationship of cooking skills to food choice. British Food Journal, 101, 590-609.

doi:10.1108/00070709910288289

Carlsen, M. H., Halvorsen, B. L., Holte, K. et al., (2010). The total antioxidant content of more than 3100 foods, beverages, spices, herbs and supplements used worldwide. Nutrition Journal Online, 9, 3. doi:10.1186/1475-2891-9-3.

Civille, G. V., \& Lyon, B. G. (1996). Aroma and flavor lexicon for sensory evaluation: Terms, definitions, references, and examples. West Conshohocken, PA: American Society for Testing and Materials (ASTM) International.

Cordain, L., Eaton, S. B., Sebastian, A. et al. (2005). Origins and evolution of the Western diet: Health implications for the 21 st century. American Journal of Clinical Nutrition, 81, 341-354.

Crawford, D., Ball, K., Mishra, G., Salmon, J., \& Timperio, A. (2007). Which food-related behaviours are associated with healthier intakes of fruits and vegetables among women? Public Health Nutrition, 10, 256-265. doi:10.1017/S1368980007246798

Fazio, V. A., \& Inge, K. E. (2006). The Health benefits of herbs and spices: The past, present, the future. Medical Journal of Australia, 185, S19-S20.

Fenech, M. (2006). Health benefits of herbs and spices: How strong is the evidence? Medical Journal of Australia, 185, S7, S9-S12.

Gardner, C. D., Messina, M., Lawson, L. D., \& Farquar, J. W. (2003). Soy, garlic, and ginkgo biloba: Their potential role in cardiovascular disease prevention and treatment. Current Atherosclerosis Reports, 5, 468-475. doi:10.1007/s11883-003-0037-7

Gruenwald, J., Freder, J., \& Armbruester N. (2010). Cinnamon and health. Critical reviews in Food Science and Nutrition, 50, 822-834. doi:10.1080/10408390902773052

Jungbauer, A., \& Medjakovic, S. (2012). Anti-inflammatory properities of culinary herbs and spices that ameliorate the effects of metabolic syndrome. Maturitas, 71, 227-239.

Kaefer, C. M., \& Milner, J. A. (2008). The role of herbs and spices in cancer prevention. Journal of Nutritional Biochemistry, 19, 347-361. doi:10.1016/j.jnutbio.2007.11.003

Kochhar, K. P. (2008). Dietary spices in health and diseases. Indian Journal of Physiology and Pharmacology, 52, 106-122.

Larson, N. I., Perry, C. L., Story, M., \& Neumark-Sztainer, D. (2006). Food preparation by young adults is associated with better diet quality. Journal of the American Dietetic Association, 106, 2001-2007. doi:10.1016/j.jada.2006.09.008

Li, Z., Henning, S. M., Zhang, Y. et al. (2010). Antioxidant-rich spice added to hamburger meat during cooking results in reduced meat, plasma, and urine malondialdehyde concentrations. American Journal of Clinical Nutrition, 91, 1180-1184. doi:10.3945/ajen.2009.28526

Lin, B., Frazao, E., \& Guthrie, J. F. (1999). Away-from-home foods increasingly important to quality of American diet. Washington: Economic Research Service.

Louisiana State University. URL (last Checked 9 September 2012). http://www.lsu.edu/ur/ocur/lsunews/MediaCenter/News/2011/03/ite $\mathrm{m} 27403 . \mathrm{html}$

Lucan, S. C., Barg, F. K., Karasz, A., Palmer, C. S., \& Long, J. A. (2012). Perceived influences on diet among urban, low-income African Americans. American Journal of Health Behavior, 36, 700-710. doi:10.5993/AJHB.36.5.12
McCormick for Chefs (2012). Flavor forecast. URL (last checked 11 October 2012).

http://www.mccormickforchefs.com/Resources/Flavor-Forecast-201 2.aspx

McCormick Recipes. URL (last checked 11 October 2012). http://www.mccormick.com/Recipes.aspx

McCormick Science Institute. URL (last checked 11 October 2012). http://www.mccormickscienceinstitute.com

New Mexico State University. URL (last checked 3 October 2012). http://aces.nmsu.edu/county/bernalillo/documents/spin-it-up-jan-201 2.pdf

Obbagy, J. E., \& Essery, E. V. (2012). The food environment, eating out, and body weight: A review of the evidence. Alexandria VA: Center for Nutrition Policy and Promotion, USDA.

Ozcan, M. M., \& Chalchat, J. C. (2009). Chemical composition and antimicrobial properties of the essential oil of Origanum saccatum 1. Journal of Food and Safety, 29, 617-628. doi:10.1111/j.1745-4565.2009.00181.x

Patch, C. S., \& Sullivan, D. R. (2006). The health benefits of herbs and spices: How strong is the evidence. Medical Journal of Australia, 185, S7-S8.

Qin, B., Panickar, K. S., \& Anderson, R. A. (2010). Cinnamon: Potential role in the prevention of insulin resistance, metabolic syndrome, and Type 2 Diabetes. Journal of Diabetes Science and Technology, 4, 685-693.

Reinagel, M. (2012). Not in your mother's spice cabinet. Food and Nutrition, 1, 14-17.

Singletary, K. (2010a). Ginger-An overview of health benefits. Nutrition Today, 45, 171-183. doi:10.1097/NT.0b013e3181ed3543

Singletary, K. (2010b). Oregano-Overview of the literature on health benefits. Nutrition Today, 45, 129-138. doi:10.1097/NT.0b013e3181 dec789

Singletary, K. (2010c). Turmeric-An Overview of potential health benefits. Nutrition Today, 45, 216-225. doi:10.1097/NT.0b013e3181f1d72c

Srinivasan, K. (2005). Plant foods in the management of diabetes mellitus: Spices as beneficial antidiabetic food adjuncts. International Journal of Food Sciences and Nutrition, 56, 399-414. doi: $10.1080 / 09637480500512872$

Sultan, M. T., Butt, M. S., Ahmad, R. S., Batool R., Naz, A., \& Suleria, H. A. R. (2011). Supplementation of powdered black cumin (Nigella sativa) seeds reduces the risk of hypercholesterolemia. Functional Foods in Health and Disease, 1, 516-524.

Tapsell, L. C. (2008). Dietary Guidelines for Health-Where do herbs and spices fit? Nutrition Today, 43, 132-137. doi:10.1097/01.NT.0000303336.60426.47

Tayyem, R. F., Heath, D. D., Al-Delaimy, W. K., \& Rock, C. L. (2012). Curcumin content of turmeric and curry powders. Nutrition and Cancer, 55, 126-131. doi:10.1207/s15327914nc5502 2

Tragoolpua, Y., \& Jatisatienr, A. (2007). Anti-herpes simplex virus activities of Eugenia caryophyllus (Spreng.) Bullock \& S. G. Harrison and essential oil, eugenol. Phytotherapy Research, 21, 11531158. doi: $10.1002 /$ ptr. 2226

United States Department of Agriculture (2010). Nutrient intakes from food: Mean amounts consumed per individual by gender and age, in the United States, 2009-2010. URL (last checked 3 October 2012). http://www.ars.usda.gov/SP2UserFiles/Place/12355000/pdf/0910/Ta ble_1_NIN_GEN_09.pdf

United States Department of Agriculture and United States Department of Health and Human Services (2010). Dietary Guidelines for Americans, 2010 (7th ed.). Washington: US Government Printing Office.

Viuda-Martos, M., Ruiz-Navajas, Y., Fernández-López, J., \& PérezÁlvarez, J. A. (2007). Chemical composition of the essential oils obtained from some spices widely used in Mediterranean region. Acta Chimica Slovenica, 54, 921-926.

Viuda-Martos, M., Ruiz-Navajas, Y., Fernández-López, J., \& PérezÁlvarez, J. A. (2011). Spices as functional foods. Critical Reviews in Food Science and Nutrition, 51, 13-28. doi:10.1080/10408390903044271

Woods, M. P. (1998). Symposium on "taste, flavor, and palatability" taste and flavour perception. Proceedings of the Nutrition Society, 57, 603-607. doi:10.1079/PNS19980088 